\title{
CONTRIBUIÇÕES FILOSÓFICAS E PEDAGÓGICAS DE BOGDAN SUCHODOLSKI (1903-1992) PARA A EDUCAÇÃO DA CLASSE TRABALHADORA
}

\author{
BOGDAN SUCHODOLSKI'S (1903-1992) PHILOSOPHICAL AND \\ PEDAGOGICAL CONTRIBUTIONS TO THE EDUCATION OF THE \\ WORKING CLASS
}

Neide de Almeida Lança Galvão Favaro ${ }^{1}$

\section{Resumo}

Resgatar as contribuições de Bogdan Suchodolski (1903-1992) para o debate da educação na atualidade é o objetivo desse artigo, resultante de pesquisas na Pós-Graduação em Educação (UFSC/CNPQ). Ele deixou uma ampla produção a ser revisitada, pois traz elementos fundamentais para a análise de uma educação voltada aos interesses da classe trabalhadora. A abordagem qualitativa e bibliográfica, pautada no materialismo histórico, levou em conta as relações concretas em que viveu e seu engajamento político em prol da consolidação do socialismo na Polônia. Ao analisar os fundamentos filosóficos das pedagogias da essência e da existência, combateu as pedagogias burguesas e as concepções utópicas e abstratas do campo educacional da esquerda. Dentre suas postulações pedagógicas estão a defesa da união entre trabalho intelectual e físico, um programa educativo pautado na ciência e o desenvolvimento da consciência socialista. O que as distingue e demarca sua importância é o fato de que tais proposições são constituídas por uma imprescindível aliança com a prática revolucionária concreta. Suas análises levaram à defesa de uma pedagogia voltada para o futuro, que fosse expressão das lutas concretas e permanentes pela alteração das condições materiais de vida.

\footnotetext{
${ }^{1}$ A autora é Doutora em Educação (UFSC) e Professora Adjunta do Colegiado de Pedagogia da UNESPAR - Campus de Paranavaí. E-mail: neidegafa@hotmail.com
} 
Palavras-chave: Pedagogia. Filosofia da Educação. Teoria Marxista. Bogdan Suchodolski.

\section{Abstract}

To rescue Bogdan Suchodolski's (1903-1992) contributions to the current education debate is the objective of this article, resultant from researches in the Postgraduate course in Education (UFSC/CNPQ). He left a vast production to be revisited, for it brings fundamental elements to the analysis of an education turned to the interests of the working class. The qualitative and bibliographical approach, based on the historical materialism, took into account the concrete relations in which he lived and his political engagement in favor of the socialism consolidation in Poland. When analyzing the philosophical fundaments of the essence and existence pedagogies, he fought the bourgeois pedagogies and the utopian and abstract conceptions of the left educational field. Among his pedagogical postulations are the defense of the union between intellectual and physical work, an education program based on science and the development of a socialist conscience. What distinguishes and demarcates his importance is the fact that such propositions are constituted by an indispensable alliance with the concrete revolutionary practice. His analyses led to the defense of a pedagogy turned to the future, meant to be the expression of concrete and permanent fights for the alteration of the material conditions of life.

Keywords: Pedagogy. Philosophy of Education. Marxist Theory. Bogdan Suchodolski.

\section{INTRODUÇÃO}

A discussão educacional direcionada para os interesses da classe trabalhadora adquire no contexto atual uma importância considerável, devido ao momento histórico que expressa a vitória do capital. $\mathrm{O}$ avanço reacionário nas diversas dimensões da sociabilidade, o recuo de conquistas históricas da classe trabalhadora e a ampliação incontrolável da concentração de riquezas e da acumulação capitalista são o reflexo visível dessa lógica societal. 
A superação dessa relação social atual é uma possibilidade histórica que se coloca para a classe trabalhadora e que depende de inúmeras condições para ser viabilizada. Discutir a educação no interior desse projeto político mais amplo é o objetivo aqui pretendido. O autor analisado problematiza propostas burguesas e utópicas presentes no campo pedagógico, fornecendo fundamentos e princípios da teoria marxista que permitem verificar os limites ainda presentes na educação contemporânea, o que justifica a escolha de sua obra para esta investigação.

Bogdan Suchodolski nasceu no sul da Polônia, em Sosnowiec, em 1903. Proveniente de uma família próspera, doutorou-se em Filosofia no ano de 1925, realizou estudos no exterior e depois de retornar à Polônia atuou na cátedra de Pedagogia da Universidade de Lvov, até a invasão nazista. Viveu os dramas da ocupação alemã (1939-1943) e a perseguição da Polícia Secreta do Estado (Geheime Staatspolizei), a Gestapo, animando a universidade clandestina.

A Polônia tornou-se depois um dos epicentros da Guerra Fria, ao compor os países do bloco socialista, quando então Suchodolski teve um importante engajamento pedagógico e político. As liberdades políticas na Polônia foram sendo gradualmente cerceadas, desta vez em virtude do terror stalinista, quando então Suchodolski foi "acusado de ser 'um erudito burguês' e tornou-se objeto de críticas cada vez mais violentas", segundo Wojnar (2010, p. 15). Mesmo durante o período de estatismo totalitário ele animou a vida intelectual por meio de associações independentes do Estado.

No âmbito da acirrada luta que marcou boa parte do séc. $X X$, entre os blocos capitalista e socialista, a produção intelectual deste pedagogo polonês 
foi considerada por Cambi (1999, p. 605) uma reelaboração construtiva da conjugação educacional entre "tradição marxista" e "princípios da ética e da fé cristã". O resultado teria sido um "humanismo realista", que trazia como temas recorrentes a perspectiva de "progresso", a recomposição social e a formação de um "homem novo", aberto à "cooperação", bem como a proposta de uma pedagogia voltada para o futuro.

Wojnar (2010) também identificou a rejeição de suas obras pelos marxistas ortodoxos, devido ao fato de considerarem que ele se apoiou nas ideias humanistas do "jovem" Marx. Além disso, suas ideias educacionais chegaram a ser algumas vezes consideradas utópicas.

Ele atuou intensamente também no campo da política educacional. Promoveu sucessivas reformas de ensino, assumiu a Presidência do Conselho Nacional de Cultura (1983), cumpriu um mandato como Deputado (1985-1989) e participou de alguns organismos internacionais, como a Organização das Nações Unidas para a Educação, a Ciência e a Cultura (UNESCO). Além disso, formou inúmeros professores, integrou associações científicas, lecionou no exterior, além de publicar mais de 40 (quarenta) obras de sua autoria, traduzidas principalmente para o italiano, espanhol, francês e inglês. No Brasil, a partir da década de 1980, seus escritos ganharam espaço e importância nas pesquisas educacionais, embora atualmente sejam escassos seus estudos. Ele faleceu em 1992, um ano após o decreto que estabeleceu o fim da União Soviética.

Esta investigação deteve-se em duas obras de sua autoria: Teoria marxista da educação, publicada na Polônia em 1957 e editada em Portugal em 1976, em três volumes; e Pedagogia e as grandes correntes filosóficas, de 1960, traduzida 
para o português em 1972. A análise de sua produção educacional aqui realizada levou em consideração a realidade concreta, marcada pelos impasses e desafios que o país tentava superar no processo de formação do bloco socialista.

O entendimento de suas proposições educacionais está vinculado ao seu projeto político e estratégico mais amplo, pois Suchodolski estava envolvido na luta pelo desenvolvimento das forças produtivas de seu país, bem como na tentativa de assegurar as conquistas políticas obtidas. Seu objetivo era superar a relação social do capital que persistia em várias esferas.

O ambiente em que produziu, segundo Paulus (2006), era marcado pelo atraso econômico e social do país, caracterizado pela falta de industrialização, de urbanização e de educação. O próprio Suchodolski fizera um balanço da situação nas comemorações do vigésimo aniversário da República Popular da Polônia e indicou que economicamente ainda havia a forte presença do capitalismo, principalmente na agricultura, pois $80 \%$ da produção se concentravam nas mãos de proprietários privados. Já outros ramos eram marcados por uma organização multisetorial, persistindo lado a lado setores estatais e corporativistas privados. Somava-se a essa conjuntura a permanência dos resquícios feudais, expressos na resistência do clero e da aristocracia parasitários, aliados a uma mentalidade medieval. No caso da educação, não havia uma rede de escolas, nem mesmo capitalistas.

Este trabalho aborda duas frentes de análise presentes nas obras selecionadas: a sua abordagem dos fundamentos filosóficos das tendências pedagógicas, que o levaram a apontar o caminho para a superação dos 
dilemas pedagógicos atuais, e as suas proposições pedagógicas efetivas, decorrentes da leitura que realizou da obra marxiana.

\section{CONCEPÇÕES PEDAGÓGICAS: BASES FILOSÓFICAS E MATERIAIS}

Quanto ao primeiro aspecto da investigação, verificou-se que sua produção intelectual analisou duas grandes concepções pedagógicas em seus fundamentos filosóficos: as pedagogias da essência e da existência. Pode-se identificá-las, respectivamente, com as chamadas "pedagogia tradicional" e "escola nova", em suas distintas vertentes. Suchodolski (2002) realizou uma discussão histórica, a partir das filosofias que lhes deram sustentação, abordando-as desde a antiguidade até o séc. XX.

Na pedagogia da essência ele identificou a preocupação em realizar o que o homem deve ser, a sua essência verdadeira, distinguindo-a do eu empírico. Descurava-se assim de tudo o que é empírico no homem e em torno do homem e a educação passava a ser concebida como medida para desenvolver tudo o que implicava sua participação na realidade ideal. Já na pedagogia da existência, levava-se em conta o conteúdo existente da vida humana, defendendo-se o livre desenvolvimento do homem. O modo de conceber essa existência foi muito diverso, mas tendeu para a liquidação de uma superestrutura normativa e para concepções individualistas. A educação foi assim identificada com o processo espontâneo de desenvolvimento, sendo as sensações e possibilidades humanas reduzidas à vida criada pela sociedade burguesa.

Por intermédio de um profundo estudo filosófico, Suchodolski (2002) localizou a base da concepção essencialista no idealismo antigo e cristão, 
mostrando como Platão (428/427-348/347 a.C.), Aristóteles (384-322 a.C.) e o cristianismo, incluindo São Tomás de Aquino (1225-1274), contribuíram para a filosofia da essência, embora com características distintas. No renascimento ele indicou um novo desenvolvimento dessa pedagogia, agora ligada às tradições laicas e racionalistas do mundo antigo, que conservou os princípios fundamentais da essência, embora admitisse concessões em relação aos seus meios.

Constatou, todavia, que quase ao mesmo tempo erguia-se uma revolta contra essa pedagogia em certas correntes ideológicas do Renascimento, com a ousadia de propor que os homens vivessem de acordo com seu pensamento, abordando as experiências humanas, os heróis populares. Suchodolski (2002) destacou Rabelais (1494-1553) e Montaigne (1533-1592) como os autores mais expressivos desse momento, pois condenavam a submissão do homem aos valores e dogmas tradicionais e eternos, tornando-se fonte de novos conceitos de homem e apontando para a pedagogia da existência.

No século XVII houve uma reação e ofensiva da pedagogia da essência, que se manteve primordial. Ela foi representada tanto pelos jesuítas, com a publicação da obra Ratio Studiorum, quanto por uma vertente mais moderna, que se manifestou na utilização da noção de natureza, numa concepção laica e científica das leis naturais. A função que a ideia tinha no sistema platônico era retomada nesse momento, mas substituída pela natureza, concebendo a essência do homem de modo metafísico e dogmático, em que a cultura exerceria a função de destruir tudo o que violasse a ordem natural. Comenius (1592-1670) foi citado como o criador do sistema pedagógico dependente da natureza, pois ela não tinha um significado empírico em sua teoria, já que era 
previamente estabelecida. Houve outras defesas de tal concepção, embora com pontos de vista distintos.

Para Suchodolski (2002, p. 32), foi na pedagogia de Rousseau (17121778) que ocorreu "a primeira tentativa radical e apaixonada de oposição fundamental à pedagogia da essência e de criação de perspectivas para uma pedagogia de existência". Pestalozzi (1746-1827) e Froebel (1782-1852), apesar de tratarem de perspectivas diferentes, deram também sua contribuição a essa tendência ao valorizarem a atividade própria da criança.

Ao mesmo tempo surgia no século XVIII outra variante da pedagogia da essência, desta vez com a filosofia de Kant (1724-1804), que pôs em evidência a atividade da criança no domínio intelectual e moral. Foi com seus discípulos que ocorreram as tentativas de reflexão no campo da educação. As obras de Fichte (1762-1814) e de Hegel (1770-1831), junto com as de Kant, foram consideradas, apesar de suas diferenças, "concepções bastante homogêneas da pedagogia da essência". (SUCHODOLSKI, 2002, p. 37).

Vieram reações imediatas e a réplica ao criticismo e ao idealismo objetivo foi totalmente diferente no século XIX, iniciando o processo de diferenciação da pedagogia da existência, que até então se encontrava em fase incipiente. As obras de Kierkegaard (1813-1855), Stirner (1806-1856) e Nietzsche (1844-1900), apesar de bastante diferentes, contribuíram para definir com mais exatidão a pedagogia da existência. Suchodolski (2002) assim sintetizou suas contribuições: Rousseau combateu a cultura da aristocracia feudal, superficial, de elite, que prejudicava a vida dos outros homens; Kierkegaard, por sua vez, foi contra os refúgios objetivados da vida religiosa para defender o máximo esforço pessoal de cada um; já Stirner e Nietzsche 
combatiam qualquer ideal ou norma comuns e defendiam a vontade egoísta dos eleitos e do menor número.

A tentativa de defender os princípios da pedagogia da essência nesse período foi marcada pelo humanismo racionalista, que continuou as aspirações dos autores do sistema nacional da cultura, encontrando traços comuns e universais na razão. O programa educativo dava prioridade à formação do espírito, base de toda a educação. Nessa concepção da pedagogia da essência, negavam-se os conceitos do idealismo antigo e do tomismo medieval, rejeitava-se o culto da tradição e repudiavam-se as especulações filosóficas subjetivas. Defendia-se, entretanto, a conveniência de estabelecer um conjunto de ideais e normas para inculcar à juventude, que teria um caráter racional, claro e bem fundamentado.

Apesar dessas tentativas, foi a pedagogia da existência que adquiriu maior vigor e importância na pedagogia burguesa desde os fins do séc. XIX. Ao tentar simplificar essa posição e suas ramificações, Suchodolski (2002) citou a teoria da evolução como um dos principais fatores de fortalecimento da pedagogia da existência, embora tal formulação também tenha sido utilizada pela pedagogia da essência. Darwin (1809-1882) no campo da natureza e Spencer (1820-1903) na área do desenvolvimento social colheram benefícios das aquisições precedentes, mas se opuseram à pedagogia da essência por seu caráter de inutilidade prática, de conservadorismo. Eles advogavam as necessidades do presente, defendendo uma educação utilitária e instrumental, que estivesse de acordo com as leis da vida social, ou seja, as leis da luta pela vida. 
A pedagogia da existência adquiria pela primeira vez o aspecto de "um sistema determinado de investigações, um conjunto de métodos e aquisições na via do conhecimento" (SUCHODOLSKI, 2002, p. 52). Nesse mesmo período o pragmatismo também desenvolvia uma concepção semelhante, embora com distinções. Foi o caso de Dewey (1859-1952) que, preocupado com os objetivos da educação, propôs a organização das experiências da criança, formando simultaneamente seu espírito e moral. Com seu imanentismo evolucionista, Dewey valorizava o presente, fonte de toda a atenção, e abolia o direito de atribuir ao futuro o papel de dirigente da vida presente.

Com a expansão da pedagogia da existência, certas correntes da pedagogia da essência incorporaram suas teorias. Isso já ocorrera com a pedagogia humanista, que fizera concessões à vida, ao tentar se aproximar das crianças, embora se limitasse a modificações da técnica educativa, sem alterar o processo educacional e suas características. A pedagogia religiosa também enveredou por este caminho, ao adotar a visão do homem como ele é, não apenas como deveria ser, o que ocasionou ataques dos tradicionalistas e uma crítica do Papa Pio XI, que denunciou os perigos do naturalismo pedagógico. Também nos autores da pedagogia da natureza se verificou esse processo, alguns dando grande importância aos instintos, mas sem alterar a imagem de natureza tradicional.

Na pedagogia sociológica, por sua vez, deixou-se de procurar fora dos fatos empíricos uma estrutura social ideal, reagindo contra os fenômenos ideais ou normativos, igualando a natureza da vida social ao conjunto dos fatos sociais reais. A teoria da educação social tornou-se assim uma teoria de 
adaptação às condições existentes, pois o modo de vida da época era a realidade formativa para as diversas doutrinas que surgiram.

Para Suchodolski (2002, p. 62), esta “existencialização” da pedagogia social "reduzia a educação a um processo de adaptação ao meio" e estava em conexão tanto "com correntes nacionalistas e com uma filosofia irracional" quanto com "diretrizes da democracia burguesa" e do "racionalismo". A partir desse fenômeno, desenvolveram-se duas grandes correntes da pedagogia da existência, que se opuseram à pedagogia da essência, uma em nome da criança e outra invocando a vida dos grupos sociais.

O autor concluiu que várias correntes pedagógicas, no decorrer do século XX, tentaram vencer as concepções individualistas e universalistas da vida e da educação, para unir a pedagogia da essência à da existência. $\mathrm{O}$ problema é que “a 'síntese' assim concebida representava no fundo o aniquilamento de tudo o que contribuía para o valor da pedagogia da existência e a pedagogia da essência", pois agora "tendia-se a camuflar" as contradições entre o desenvolvimento do indivíduo e a vida social, bem como “a persuadir os indivíduos que ao submeterem-se às condições existentes realizavam uma obra profundamente justa e criadora" (SUCHODOLSKI, 2002, p. 97). Tentava-se minimizar ou ignorar as contradições reais que a sociedade burguesa criava entre a existência humana e seu ideal, justificando-as com uma noção que preconizava uma solução concebida a partir do individual e ideal, sem considerar necessário e primordial a alteração concomitante das relações sociais concretas.

Após indicar os conflitos seculares entre as duas pedagogias e as tentativas falhas de conciliação entre ambas, próprias do século $X X$, concluiu 
que a contradição entre a existência social do homem e sua essência, entre a vida e o ideal, necessárias a uma educação criadora e dinâmica, só seriam possíveis mediante uma aliança entre "a atividade pedagógica" e "uma atividade social" que criasse as condições históricas e sociais necessárias. A teoria marxista fornecia a chave para essa superação, pois, em sua perspectiva,

[...] o pensamento pedagógico perde-se quando escolhe a pedagogia da existência, quando opta pela pedagogia da essência e quando tenta unir estes dois princípios em função das condições históricas e sociais existentes. A pedagogia devia ser simultaneamente pedagogia da existência e da essência, mas esta síntese exige certas condições que a sociedade burguesa não preenche, exige também que se criem perspectivas determinadas de elevação da vida cotidiana acima do nível atual. $O$ ideal não deve nem sancionar a vida atual, nem tomar uma forma totalmente alheia a essa vida. (SUCHODOLSKI, 2002, p. 98, grifos nossos).

O pedagogo polonês justificou esta posição com o argumento de que o fator decisivo que limita e destrói essa síntese é a propriedade privada, pois é ela que torna os indivíduos unilaterais ao valorizar a luta pela posse, alienando os sentidos pelo ter. Só com o fim da propriedade privada seria possível emancipar os sentidos e as propriedades humanas, pois é isto que torna possível reconhecer nas coisas os produtos sociais humanos, como expressões da essência e da vida humana. Este é um dos pontos basilares de sua proposta educativa como um todo, que não pode ser ignorado sob o risco de se perder a radicalidade de sua contribuição. Ela permite repensar postulações educacionais que procuram realizar a síntese de tais concepções pedagógicas na atual sociedade, mesmo em detrimento da alteração das condições objetivas para sua viabilidade.

O derrube da propriedade privada era para ele a tarefa do comunismo e criaria a base de um ensino humano, além de permitir que o homem 
compreendesse que sua atividade é a criação de um mundo humano. Isso porque é seu próprio desenvolvimento e enriquecimento que o lança para outras atividades, e não a simples produção de bens para exploração imediata, egoísta e para conversão em propriedade privada. Ao se apropriar do conteúdo humano do mundo socialmente criado, se humanizará cada vez mais, pois só assim "toda a riqueza do patrimônio histórico da humanidade, cujo carácter de obra humana foi esquecido durante tanto tempo, converter-seá na escola do homem". (SUCHODOLSKI, 1976c, p. 26).

A teoria de Marx (1818-1883) e Engels (1820-1895) permitiu que os problemas pedagógicos fossem analisados do ponto de vista da classe trabalhadora. A questão a ser considerada, no entanto, é que no âmbito da relação do capital as orientações pedagógicas inspiradas nesta teoria acabaram muitas vezes adotando "caminhos estreitos" e insuficientes.

[...]. Este carácter humanístico-utópico do pensamento pedagógico, que tenta, no seio da sociedade burguesa, ultrapassar as suas limitações classistas não leva consigo as premissas materiais para uma acção consciente e revolucionária das classes oprimidas.

A atividade de Marx e Engels, que conduziu ao ressurgimento do socialismo científico, constitui, por sua vez, uma atividade que supera esta pedagogia humanístico-utópica e torna possível conceber o problema do homem e da educação nas categorias de uma análise científica do desenvolvimento social e da prática revolucionária. (SUCHODOLSKI, 1976c, p. 144-145).

Foi na obra desses autores que Suchodolski identificou as pistas para ultrapassar os limites das pedagogias em vigor, pseudo-humanísticas, que não alteram e se recusam a ver a estrutura fundamental de classe. Uma pedagogia qualitativamente nova necessitava estar vinculada aos princípios do materialismo histórico e à luta revolucionária. 
Uma "educação virada para o futuro" (SUCHODOLSKI, 2002) recusavase a aceitar o status quo e caracterizava-se por estar necessária e irremediavelmente associada a uma atividade social que o transformasse, que criasse as condições para que a existência do homem se tornasse fonte e matéria-prima da sua essência. Tal proposição persiste na sua análise pedagógica, apresentada a seguir. Ela reflete suas lutas concretas em meio a um contexto material de tentativa de implantação do socialismo nos países do bloco soviético, por isso sua análise requer o necessário rigor científico, a fim de evitar simples transplantes anacrônicos de propostas histórica e politicamente situadas.

\section{PEDAGOGIA, MARXISMO E O PROJETO REVOLUCIONÁRIO}

Dentre as diversas discussões realizadas pelo autor, algumas proposições educativas para a classe trabalhadora se destacaram em suas obras. A primeira delas é a importância da ligação do trabalho físico e do ensino para as crianças, pois oportunizaria a união da teoria com a prática, assegurando assim o amplo desenvolvimento humano. Neste aspecto o autor se alinhou com a concepção que orientava as políticas educacionais do bloco oriental, de fonte marxista. Tal enunciado persiste em grande parte das proposições educacionais da esquerda e se constitui pela "referência à unidade entre escola e vida, cultura e trabalho". (CAMBI, 1999, p. 604).

Suchodolski (1976b, p. 18) considerou que a teoria marxiana apreendeu "os valores gerais que consistem na ligação entre trabalho físico e o ensino", mesmo diante das condições insuportáveis de trabalho e estudo das crianças do século XIX. Ele se diferenciou de outros defensores deste princípio, todavia, 
ao trazer exigências para que tal proposta se efetivasse. Ele preconizou, por exemplo, "que no capitalismo" tais valores "não só não podem se desenvolver mas que são precisamente destruídos". Isso porque o trabalho é aí convertido em objeto de exploração, atrofiando as possibilidades do ensino.

Já no socialismo, Suchodolski (1976b, p. 19) concebia que tanto "a produção mecanizada se converte em elemento de libertação e desenvolvimento do homem" quanto "a ligação entre o ensino e o trabalho produtivo" adquire "um alto valor educativo". No cerne da questão estava o problema da relação do capital, pois nesta as possibilidades de ensino que surgem com o desenvolvimento das forças produtivas ficam atrofiadas, assim como o elemento revolucionário da própria produção, que está em aguda contradição com a organização do trabalho capitalista. A natureza humana é aí destruída porque o trabalho físico fica separado dos elementos espirituais e a atividade intelectual fica à margem do trabalho físico. Desconsiderar essa realidade concreta sob o capital é o que conduz aos erros do idealismo artificial e da falsa abstração.

Ele delimitou assim a diferença radical entre as ideias burguesas de ligação do trabalho ao ensino, que servem para fins filantrópicos ou ideologias reformistas, e "a concepção marxista de tal ligação, que só pode desenvolver-se por completo através do moderno desenvolvimento das forças produtivas na sociedade socialista" (SUCHODOLSKI, 1976b, p. 25, grifos nossos). A seu ver, portanto, só a revolução socialista poderia tratar de modo prático a questão da educação do homem para o trabalho e só ela poderia quebrar as cadeias que impedem o desenvolvimento das forças produtivas. Este princípio traz uma importante 
distinção entre a sua posição e a de propostas pedagógicas da esquerda contemporânea, que desconsideram tal necessidade concreta.

O autor avançou em relação às propostas "humanistas" e à "utopia" pedagógica com um constante alerta: o de que a educação marxista só pode ser concretizada na prática revolucionária. Ao recomendar a relação do trabalho produtivo com a educação, deixava claro que esta união só seria possível após a eliminação da divisão do trabalho dominante na sociedade de classes. Foi por isso que ele ressaltou que a ligação entre o ensino e o trabalho produtivo é apenas um dos elementos fundamentais do programa educativo defendido pelo marxismo clássico. “O segundo elemento fundamental é o princípio da ligação entre a educação, o ensino e a actividade revolucionária da classe operária" (SUCHODOLSKI, 1976b, p. 37, grifos nossos). Isso porque a concepção marxista da luta contra o capitalismo implica afastar todo o programa utópico, que não expressa nenhuma medida para a realização das ideias defendidas.

[...] O princípio fundamental de Marx e Engels era ligar o mais estreitamente possível o socialismo científico e a luta revolucionária da classe operária e organizar esta luta como o único caminho que conduz ao socialismo. A separação de esperanças utópicas, aspirações ou intenções de organizar as «futuras» comunidades no seio da actual sociedade e a política concreta da luta revolucionária que conduz à abolição das relações existentes são algo tão primordial que, naturalmente, tinha que afectar também as questões do ensino. É evidente que a educação dos homens na base do socialismo utópico tinha que ser algo totalmente diferente da educação nos princípios da luta de classe do proletariado. (SUCHODOLSKI, 1976b, p. 27, grifos nossos).

Essa vinculação requereu de Marx e Engels um intenso trabalho de desenvolvimento da consciência ideológica e política dos operários, aliado à 
definição do processo de luta nas situações concretas. Exigiu o derrube dos obstáculos e o distanciamento de concepções inimigas, repelindo os ataques da burguesia liberal e combatendo o programa da pequena burguesia. Além disso, foi necessário contestar as tentativas de reconciliação e compromisso, desmascarando as tendências anarquistas e conspirativas, que defendiam uma ação revolucionária espontânea, sem condições objetivas. Eles se opunham a tudo isso e uniam "o princípio da luta revolucionária à análise serena e precisa da realidade social, a uma estratégia e táctica ponderadas" (SUCHODOLSKI, 1976a, p. 28), com base nas leis de desenvolvimento histórico e que condensa no proletariado a possibilidade de libertação de toda a sociedade.

Segundo o autor, seria na luta pela nova ordem social que se forjariam a consciência e o desenvolvimento do proletariado, cuja exigência era que a filosofia se convertesse em sua arma espiritual. Por isso, era imprescindível o combate à idealização utópica do próprio proletariado, já que sua tarefa era determinada pelo desenvolvimento histórico objetivo e dependia da sua disposição consciente e ativa.

Na mesma linha de argumentação defendeu outro aspecto, que foi a importância da cultura e da ciência, criticando a indiferença dos operários a todas as teorias e retomando a crítica marxiana à aversão de Bakunin (18141876) a ambas. Suchodolski (1976b) alertou que para a teoria marxista era necessário o conhecimento correto da realidade e a livre investigação científica, que deveriam partir da base real.

Os teóricos da classe operária, com base nesses princípios, não poderiam ser utopistas, formulando sistemas e uma ciência regeneradora, dogmatizando a teoria marxista, à margem do desenvolvimento do movimento operário 
revolucionário. “Enquanto só perseguirem a ciência e só construírem sistemas, enquanto permanecerem no começo da luta, não verão mais que miséria na miséria, sem captarem dela o aspecto revolucionário e capaz de provocar o derrube da antiga sociedade" (SUCHODOLSKI, 1976b, p. 49). Preconizava assim que só a união da educação e da ação revolucionária possibilitaria o progresso social e também o avanço no campo das ciências econômicas e sociais.

Por isso advogava que não se poderia nem abandonar o movimento operário em seu instinto revolucionário, nem converter os princípios do socialismo científico em especulações arbitrárias dos cientistas que se oferecem às massas. Suchodolski (1976b, p. 52-53) concluiu que a solução se daria pela unidade dialética da teoria e da prática revolucionárias, que são "a base de todas as disposições ou medidas para a formação da consciência socialista dos operários" e para a determinação dos princípios do trabalho ideológico e político.

Prevenir-se contra a falsificação burguesa de uma cultura geral e autônoma, bem como "contra todas as falsificações que provêm das falsas abstracções ou da aceitação da espontaneidade" (SUCHODOLSKI, 1976b, p. 53) era condição sine qua non para a efetivação dessa meta educativa. Para o autor, o que determinaria a permanência de uma dada cultura na história não eram suas propriedades, mas o fato de estarem estreitamente ligadas à realidade. Nessa perspectiva, superava a ilusão do educador sobre sua missão como expositor da cultura, do patrimônio histórico dos grandes criadores, ligando a consistência e a variabilidade da cultura à persistência e à variabilidade da vida social. $\mathrm{O}$ combate às concepções especulativas e 
generalistas era necessário, portanto, porque a educação não era uma questão de "ensino dos bens culturais", mas sim "a formação de combatentes para o progresso social", o que só se daria pela "participação nessa luta". (SUCHODOLSKI, 1976b, p. 126).

Conforme o autor, tal teoria "dirige a atenção do educador para os problemas da situação social, material de classe dos homens na prática e na teoria, para os problemas do seu trabalho produtivo e para os processos de formação das suas representações e concepções na vida real diária". (SUCHODOLSKI, 1976a, p. 114).

O seu programa de ensino para a classe proletária tinha como exigência, portanto, a necessária ligação da educação científica, da formação cultural, com a atividade revolucionária, a fim de contribuir para superar as ilusões que impedem a transformação revolucionária.

Deste modo surgiu uma dependência dialéctica entre as análises e a crítica da tradição cultural e a actividade político-social da classe operária. Este vínculo dialéctico, como base do programa de ensino, foi oposto por Marx e Engels à escola burguesa e às suas mentirosas frases de uma «cultura geral».

Neste programa, os chamados valores de uma cultura geral humana perderam o seu carácter autônomo. É evidente que eles não constituem mais que uma máscara dos interesses burgueses e que uma classe de tradição viva e valiosa materializa [...]. (SUCHODOLSKI, 1976b, p. 61, grifos nossos).

A transmissão da cultura como tarefa da educação foi assim radicalmente problematizada pelo autor, que indicou enfaticamente a necessidade de realizar uma crítica da tradição cultural, devido aos limites de uma suposta "cultura geral" e "neutra". Essa exigência para o ensino era imprescindível para não trair os interesses da classe trabalhadora. 
A base para um ensino humano, omnilateral, trazia ainda em si a condição do mesmo estar aliado à luta pelo derrube da propriedade privada, pois é ela que limita e destrói as relações dos homens com o mundo. Apenas a participação da educação nas divergências ideológicas, portanto, era insuficiente. Suchodolski (1976c) combateu assim os que pretendem transformar a sociedade reeducando a consciência, mas também foi contra os que preconizam que se deve esperar até a obra socialista ser realizada. A tarefa do ensino era a de cooperar na luta contra a ordem opressiva do capital, e não a de criar homens novos em condições isoladas e artificiais.

Realizava assim uma aguda denúncia contra as tendências conciliadoras, os compromissos que ocultam as diferenças de classe e difundem a opinião da superfluidez dos métodos revolucionários, advertindo contra a adaptação utilitarista às relações capitalistas e organizando a luta da classe trabalhadora no campo da educação. Em suas palavras,

[...] Marx fez uma verdadeira revolução copernicana na pedagogia ao indicar que não é a vida que gira à volta das ideias, mas que são as ideias que giram à volta da vida. A partir deste momento, a pedagogia deve conceber principalmente a vida e não a Ideia. Deve conhecer os homens reais sob condições concretas e não as ideias dos homens e da cultura. Isto é a verdadeira 'revolução copernicana' em pedagogia. (SUCHODOLSKI, 1976b, p. 89).

Para o autor, Marx indicou modos de pensar científicos que vão do concreto ao abstrato, propondo generalizações obtidas a partir da realidade e que devem ser verificadas de novo quando muda a realidade de que foram extraídas, advertindo contra a autonomização das abstrações obtidas. Combateu assim também as concepções especulativas e generalistas, por se constituírem em um obstáculo à investigação científica. 
O único caminho para a verdadeira formação de homens novos estava na obrigação de contrair um pacto com a prática revolucionária do movimento operário. Esse é o elemento principal que demarca toda sua análise da teoria marxista da educação e que não pode ser perdido na sua obra.

Em oposição às fantasias utópicas, Marx indica claramente a interdependência entre o futuro e a actualidade: $<<$ A coincidência da transformação das circunstâncias e da atividade humana só pode ser compreendida como prática transformadora.>> Isto significa que o ensino só pode, actualmente, servir o futuro, quando vai unido à prática revolucionária que cria este futuro e não apenas $<<$ porque a classe dominante não pode ser derrubada de outro modo, mas também porque a classe a derrubar só pode, mediante uma revolução, desfazer-se da imundície e capacitar-se para a nova fundação de uma sociedade >> Toda a actividade política prática de Marx se baseou neste princípio fundamental da educação dos homens no decorrer da luta revolucionária. (SUCHODOLSKI, 1976c, p. 178).

Ao demonstrar que a libertação das ilusões da consciência só é possível pela transformação real das condições materiais, que são a base das ilusões, preconizou que o ensino eficaz deve contribuir no derrube, na transformação dessas condições. A ordem classista e suas contradições, portanto, não podiam ser superadas apenas no campo ideológico:

[...]. Exige uma superação de qualquer contradição real da existência; requer, pois, um tal domínio das relações sociais que de força estranha, que escraviza os homens, as transforme em expressão da sua actividade consciente. Somente deste modo podemos sair da confusão da filosofia e da pedagogia que ou degrada a realidade a favor de representações ideais ou desiste de todos os postulados morais a favor de uma obediência passiva à realidade existente [...]. (SUCHODOLSKI, 1976a, p. 151, grifos nossos).

Qualquer crítica consistente deve conduzir à crítica revolucionária e à transformação das relações que formam o seu fundamento, não se resumindo 
ao combate das ilusões da consciência. Assim Suchodolski (1976c) retomou de Marx a indicação de um caminho totalmente diferente do intelectualismo. Isto porque o marxismo considera que a consciência não é a base, mas sim o produto do trabalho humano, de suas condições diárias de vida. Uma reforma da consciência sem reformar a vida social seria, portanto, totalmente ineficaz. Sua teoria concebia que a consciência não era objeto exclusivo da atividade do educador, ela era expressão das condições materiais de vida.

O materialismo histórico permite, portanto, superar as teorias humanistas, utópicas e oportunistas, indicando o papel da atividade prática e principalmente revolucionária, já que ela transforma a realidade social dos homens e, em certo sentido, a cria. Isso significa não perder de vista que a formação da consciência de classe não depende apenas de uma teoria, ou da aquisição da cultura erudita pela escola, nem aos fatores exclusivamente subjetivos, pois ela só se (trans)forma na relação social que configura a produção da sua existência. É necessário considerar que o "ser da classe é um ser em movimento, ceifado de contradições e seu processo de consciência também, que só pode ser compreendido no interior da totalidade de suas relações e não isoladamente". (IASI, 2011, p. 125).

É no decorrer de uma luta que promova o revolucionamento das relações materiais, portanto, que se articula a classe e sua consciência revolucionária. Marx e Engels (2007, p. 48) foram cristalinos ao postular que a “existência de ideias revolucionárias numa determinada época pressupõe desde já a existência de uma classe revolucionária [...]". Vincular a educação humana apenas aos aspectos gnosiológicos, intelectuais, sem a articulação indispensável com a luta revolucionária, configura uma inversão idealista que 
se distancia do projeto socialista marxista. Eis mais um elemento importante a se considerar nas propostas educativas voltadas para os interesses das classes trabalhadoras.

Relacionado a esse pressuposto, o autor polonês ainda problematizou a questão da formação docente, combatendo qualquer visão idealista. Sem os princípios basilares acima indicados, acreditava ser impossível “a resolução do problema básico da 'educação do educador' e há que acreditar que ou os 'novos e educadores' surgem de algum sítio ou a sociedade existente, isto é, a classe dominante, os forma" (SUCHODOLSKI, 1976c, p. 35). Em decorrência disso é que o princípio diretivo proposto pelo autor para o trabalho educativo era o de que ele deveria ser cumprido com o espírito de luta política, por uma transformação radical e paralela, das circunstâncias e dos homens.

Constata-se nessa análise que as postulações educacionais de Suchodolski trazem a marca de seu projeto político mais amplo, de caráter socialista. Só em seu interior elas podem ser devidamente apreendidas. Por isso, conhecer seu projeto revolucionário torna-se importante para os objetivos aqui pretendidos.

Ao destacar na contribuição marxiana o combate aos pequenoburgueses democratas o autor apresentou elementos fundamentais de seu projeto. Suchodolski (1976b, p. 33) afirmou que era necessário "fazer com que a revolução seja permanente, até que as classes possidentes em maior ou menor grau estejam desapossadas do seu domínio". Para ele, a revolução era o resultado de uma larga luta revolucionária, era a última etapa da ação revolucionária da atualidade, era a prática revolucionária, por isso era a atividade concreta que se realizava sob condições opostas às representações 
ideais do futuro. Tal formulação constituía, a seu ver, a tese fundamental da tática político-ideológica marxista, que era portadora de um grande significado educativo.

A tese da "revolução permanente" era colocada em oposição às ilusões utópicas do papel essencial e autônomo da educação e do ensino na transformação social. "Esta revolução é o único caminho para a nova sociedade e simultaneamente a única fonte criadora de um ensino que conduza à educação de verdadeiros homens" (SUCHODOLSKI, 1976b, p. 72, grifos nossos). Como a formação humana era produto das pressões das relações econômicas e políticas, ela só poderia ser resultante da luta de classes. Este princípio, oriundo de sua análise do materialismo histórico, permitia que a teoria marxista superasse os socialistas utópicos, o socialismo verdadeiro, o oportunismo, o anarquismo e as concepções idealistas de ensino.

Um fundamento basilar de sua luta política naquela conjuntura específica foi, assim, a defesa da revolução permanente. Verifica-se que ele não aderiu à posição de alguns intérpretes gramscianos, que preconizam a superação dessa estratégia pela "guerra de posições". No Brasil, por exemplo, entre alguns educadores aliados às lutas da classe trabalhadora, a guerra de posições adquiriu intensa importância e foi associada a uma tarefa de caráter gnosiológico e ideológico. Tal posição foi oriunda de uma determinada leitura de Gramsci (1891-1937), que acabou atribuindo assim uma importância fundamental à educação.

A título de problematização, retoma-se aqui brevemente a origem dessa interpretação no Brasil, marcada por um processo de apropriação problemático da obra de Gramsci, ocorrido a partir da década de 1970. Este foi 
eivado de limites que impossibilitaram a apreensão da obra do revolucionário italiano e de todo o seu alcance. Dias (1996, p. 110) destacou os mais importantes: o imenso desconhecimento de sua vida e das lutas que travou; "o brutal abismo entre a história do movimento comunista internacional e a forma pela qual o PCB", bem como "quase todos os partidos comunistas, tratava esses problemas e a sua historiografia"; bem como o modo como foram editadas suas obras no Brasil, o que acrescentou outros problemas além dos da edição italiana.

Alguns elementos para o avanço dessa discussão e suas implicações para a esquerda brasileira e seu projeto educativo não serão aqui explorados devido aos limites deste trabalho. Cabe indicar, no entanto, a intensa influência de uma determinada interpretação gramsciana entre os educadores progressistas. Nosella (2010, p. 195) relata que houve uma verdadeira "moda gramsciana", devido à "abertura política", que permitiu estudos do marxismo nas escolas. Gramsci serviu para as esquerdas brasileiras diante de suas transformações:

[...] A particular concepção revolucionária de Gramsci, que privilegiava a 'guerra de posições' (guerra ideológica e de convencimento) à 'guerra de movimentos' (guerrilhas e golpes de Estado), se adequava cada vez melhor às esquerdas brasileiras que abandonavam, a partir de meados dos anos 70, a experiência das guerrilhas urbanas e rurais. Mais ainda: Gramsci se apresentava aos pedagogos com uma imagem de marxista moderno, um mártir do fascismo, um educador humanista, terno com os entes queridos, compreensivo e solidário com os amigos. Em certos círculos, Gramsci adquiria até o perfil de um educador no sentido próprio do termo, isto é, de um 'pedagogo'. (NOSELLA, 2010, p. 195). 
O primeiro ciclo de sua difusão no Brasil, que segundo Dias (1996) prosseguiu até a metade dos anos de 1970, foi marcado por um Gramsci caracterizado como "filósofo da práxis", portador de uma leitura humanista e historicista do marxismo, distinta da soviética até então imposta. Ele aparecia ao lado de Lukács (1885-1971) e Sartre (1905-1980), utilizados numa luta cultural antidogmática, porém centrada na filosofia, na estética, na crítica da cultura. Dias (1996) concluiu que sua apresentação era a de um político e intelectual italiano que trabalhava questões relativas aos intelectuais e à cultura, sem se referir a sua atuação política, sem localizá-lo no interior da prática e da teoria marxista, para um público que desconhecia a história dos partidos comunistas, com algumas exceções, resultando em pouca ou nenhuma eficácia política.

A interpretação de Gramsci e de sua estratégia política, como é possível deduzir, é um complexo debate em aberto, que envolve as opções políticas adotadas pelos autores. É preciso avançar no conhecimento de sua concepção, bem como no conhecimento do real, evitando sua declamação, sua leitura instrumental, que reduz seu texto a verdades que se quer provar. $\mathrm{O}$ fato a destacar neste trabalho é que não dá para ignorar ou subestimar "a importância das lutas e das práticas das classes", porque os autores "não estão sós na cena da história", já que "a teoria só se faz arma quando penetra e é penetrada pelas classes". (DIAS, 1996, p. 107).

Sem pretender aqui dogmatizar a tese de ambos, que trazem as marcas de cada momento histórico específico - um na Itália, no início do séc. $X X$, num processo revolucionário de superação do capital e o outro na Polônia no final 
do séc. $X X$, na tentativa de implantação do socialismo -, espera-se que esses elementos possam lançar luzes ao debate político e educacional atual.

No caso de Suchodolski, a necessidade da revolução permanente foi afirmada em diversos momentos, pois a considerava indispensável para superar o capital. Por isso a aliança entre a pedagogia e a revolução permanente mantinha-se inclusive no período de construção socialista, próprio de seu país. Tal perspectiva trazia como núcleo central da tarefa pedagógica ajudar a criar as condições para que pudesse servir ao futuro, o que só seria possível com a transformação paralela das relações sociais e dos homens.

[...]. Na sociedade capitalista significa: pacto do educador com a prática revolucionária do movimento operário. Na sociedade que constrói o socialismo significa: pacto do educador com as forças mais activas do progresso social que eliminam as sobrevivências da ordem capitalista superada e criam as bases de uma nova ordem. (SUCHODOLSKI, 1976c, p. 179).

Havia dificuldades e limites identificados na atuação pedagógica efetiva na Polônia, que impediam muitas vezes a superação das sobrevivências da consciência burguesa e a consolidação do novo conteúdo socialista então em desenvolvimento. Para orientar tal tarefa, ele sustentou que a vinculação do ensino à atividade revolucionária constituía o princípio educativo mais importante e inesgotável.

Trazer essas discussões, ainda que brevemente, contribui para os debates em torno da problemática da educação e seu projeto estratégico socialista na atualidade. Suchodolski forneceu pistas valiosas para evitarem-se análise a-históricas, formais e abstratas, tanto em relação à realidade brasileira 
quanto em relação à educação em geral. A historicidade de suas formulações estratégicas e táticas não pode ser ignorada, a fim de não comprometer sua teoria. As suas lutas educacionais estavam articuladas e subordinadas a um projeto estratégico mais amplo de superação do capital, dependiam da consideração da realidade concreta, o que exigia uma interpretação precisa da mesma.

\section{CONSIDERAÇÕES FINAIS}

Há inúmeras contribuições possíveis de explorar na obra de Suchodolski para o debate de uma educação voltada à classe trabalhadora na atualidade. Algumas delas foram abordadas neste trabalho, devido a sua pertinência para o avanço do debate atual. Dentre suas propostas educativas práticas aqui identificadas estão a vinculação do trabalho escolar com o trabalho produtivo, um programa de ensino baseado na ciência e também o desenvolvimento omnilateral dos homens. Um dos aspectos a considerar nesse debate, todavia, é a sua posição divergente em relação a muitas posturas educacionais da esquerda em vigor, que advogam a possibilidade de efetivar tais propostas mesmo no âmbito da sociabilidade do capital, desconsiderando a necessária e fundamental vinculação desse processo educativo com a luta revolucionária concreta.

Ao realizar uma análise crítica dos fundamentos filosóficos da pedagogia burguesa e das concepções utópicas e abstratas, o autor polonês deu também indicativos históricos e filosóficos para pensar uma nova pedagogia, desde que esta estivesse aliada a uma ação política concreta. Novamente diferenciando-se dos debates educacionais correntes, mesmo 
daqueles inscritos no campo marxista, deixou claro que o problema não era apenas de ordem teórica. Afastando-se de concepções utópicas, preconizou que o derrube da ordem capitalista era a condição para uma educação que desenvolvesse o homem plenamente. Ele destacava essa necessidade inclusive no interior das tentativas socialistas em vigor no seu contexto material. A ação revolucionária permanente era fundamental para o cumprimento dessa tarefa histórica.

Suchodolski destacou que a teoria de Marx e Engels estava relacionada à atividade revolucionária dos mesmos e este era o ponto central para as principais questões da pedagogia. Preconizou que a educação é um dos fatores mais importantes para a criação de uma nova sociedade, desde que esteja necessariamente unida à concreta prática revolucionária. Na abordagem de suas proposições, levando em conta o contexto econômico e político de suas formulações, bem como seu alerta para as necessárias mediações práticas e políticas para sua concretização, defende-se aqui a impossibilidade de simplesmente transpô-las para nossa realidade. Sua contribuição é no sentido de fornecer um importante indicativo dos limites concretos para a efetivação de aspirações pedagógicas, aparentemente críticas e inovadoras, mas que ficam à margem da necessária e concomitante alteração da relação social pautada nos fundamentos do capital.

O autor polonês viveu a construção e a derrocada da experiência que tentou implantar o socialismo e participou ativamente desse processo concreto de luta. Ele apresenta contribuições imprescindíveis para uma avaliação e revisão das experiências e propostas em curso no âmbito do trabalho pedagógico, a fim de evitar o risco das mesmas incorrerem tanto no idealismo 
reformista quanto no pessimismo imobilista. Ao preconizar a necessária ligação da teoria pedagógica com a prática revolucionária o autor desafia os educadores ao desenvolvimento de proposições pedagógicas que estejam articuladas a um projeto político mais amplo, para que assim, de fato, se possam superar as relações sociais que impedem o pleno desenvolvimento do gênero humano.

\section{REFERÊNCIAS}

CAMBI, Franco. História da pedagogia. São Paulo, SP: Editora UNESP, 1999. (Encyclopaidéia).

DIAS, Edmundo Fernandes. Sobre a leitura dos textos gramscianos: usos e abusos. In: . O outro Gramsci. São Paulo, SP: Xamã, 1996. p. 105-119.

IASI, Mauro Luís. Educação, consciência de classe e estratégia revolucionária. Universidade e Sociedade, DF, ano XXI, n. 48, p. 122-130, jul. 2011.

MARX, Karl; ENGELS, Friedrich. A ideologia alemã. São Paulo, SP: Boitempo, 2007.

NOSELLA, Paolo. A escola de Gramsci. 4. ed. São Paulo, SP: Cortez, 2010.

PAULUS, Jorge Gregório. Por uma educação voltada para o futuro: a teoria marxista de Bogdan Suchodolski. 2006. 97 f. Dissertação (Mestrado) Programa de Pós-Graduação em Educação. Universidade de Passo Fundo, Passo Fundo, 2006.

SUCHODOLSKI, Bogdan. A pedagogia e as grandes correntes filosóficas: a pedagogia da essência e a pedagogia da existência. Tradução Rubens Eduardo Frias. São Paulo: Centauro, 2002.

- Teoria marxista da educação. Tradução de Maria Carlota Melo. Lisboa: Editorial Estampa, 1976a. V.I. 
SUCHODOLSKI, Bogdan. Teoria marxista da educação. X Tradução de José Magalhães. Lisboa: Editorial Estampa, 1976b. V.II.

Teoria marxista da educação. Tradução de Francisco Paiva Boleo.

Lisboa: Editorial Estampa, 1976c. V.III.

WOJNAR, Irena. Bogdan Suchodolski (1903-1992). In: MAFRA, Jason Ferreira (Org.). Bogdan Suchodolski. Recife, PE: Fundação Joaquim Nabuco, Editora Massangana, 2010. p. 11-35. Disponível em:

$<$ http://www.dominiopublico.gov.br/download/texto/

me4662.pdf $>$. Acesso em: 08 ago. 2012.

Recebido: 27 de março de 2017

Aceito: 24 de abril de 2017

Publicado: 10 de maio de 2017 